\title{
О НЕКОТОРЫХ ВОПРОСАХ ОБЕСПЕЧЕНИИ ЭФФЕКТИВНОГО ВЗАИМОДЕЙСТВИЯ ОРГАНОВ ГОСУДАРСТВЕННОГО УПРАВЛЕНИЯ И БИЗНЕСА В ЦЕЛЯХ РЕАЛИЗАЦИИ ПРИОРИТЕТНЫХ НАЦИОНАЛЬНЫХ ПРОЕКТОВ НА ТЕРРИТОРИИ РОССИЙСКОЙ ФЕДЕРАЦИИ
}

\begin{abstract}
Аннотация: Настоящая статья посвящена исследованию вопросов обеспечения эффективного взаимодействия органов государственного управления и бизнеса в целях реализации на территории Российской Федерации приоритетных наииональных проектов. Автор считает, что сохранение Россией государственного суверенитета и независимости возможно лишь при условии осуществления структурной модернизации экономики страны и повышения качественного уровня жизни ее населения. Подобные преобразования могут быть осуществлены только благодаря объединению усилий государства и общества на пути реализаџии в Российской Федераџии комплекса приоритетных национальных проектов. Важнейшую роль в этих процессах, по мнению автора, должен играть российский бизнес. В статье исследуются проблемы, стоящие на пути взаимодействия и сотрудничества органов государственного управления и частных хозяйствующих субъектов в деле реализации приоритетных национальных проектов, разработаны и обосновываются мероприятия по их скорейшему преодолению.
\end{abstract}

Review: This article is devoted to the issues regarding guarantees of efficient interactions between the state government bodies and businesses in the sphere of implementation of priority national projects in the Russian Federation. The author considers that it is possible for the Russian Federation to keep its sovereignty and independence on the condition that its economy shall be structurally modernizes and the quality of living standard of its people shall be improved. These changes may only be implemented thanks to the joint efforts of the state and society by implementing priority national projects in the Russian Federation. Russian businesses should play the most important role in these processes. The article includes analysis of the obstacles in the way of cooperation of the state government bodies and private economic entities in the sphere of implementation of priority national projects, and the author also makes propositions for the measures to overcome these obstacles as soon as possible.

Ключевые слова: Юриспруденция, независимость, приоритетные национальные проекты, государственный суверенитет, модернизаиия, государственный суверенитет, национальная безопасность, устойчивое развитие, уровень жизни населения, бизнес

Keywords: jurisprudence, independence, priority national projects, state sovereignty, modernization, national security, sustainable development, living standard, business.

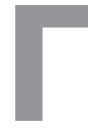
лобальный экономический кризис, который коснулся и Российской Федерации, обнажил в нашей стране целый ряд социально-экономических проблем, большая часть из которых касается роста технологической отсталости России от развитых зарубежных государств, зависимости ее экономики от реализации продукции топливно-энергетического комплекса и добывающих отраслей промышленности, значительного падения уровня жизни большинства граждан, сопровождаемого стремительным социальным расслоением в обществе. Представляется, что сохранение Российской Федерацией в этой связи своего государственного суверенитета и незави- 


\section{Национальная безопасность $4(27) \cdot 2013$}

симости требует незамедлительной структурной модернизации экономики и качественного улучшения уровня жизни населения. Осуществление подобных грандиозных преобразований возможно лишь при условии консолидации усилий общества и государства, что, в свою очередь, требует оптимизации системы государственного управления и повышения эффективности координации властью деятельности бизнеса.

Важнейшей точкой объединения усилий государственного аппарата и частного бизнеса может выступить их эффективное взаимодействие в деле разработки и реализации приоритетных национальных проектов, являющихся, как справедливо отмечает глава государства Д.А. Медведев, одним из национальных приоритетов развития Российской Федерации на ближайшие годы. [1] Причем, речь идет не только о четырех национальных проектах, обозначенных еще вторым Президентом России В.В. Путиным и уже реализуемых на территории страны («Образование», «Здоровье», «Доступное и комфортное жилье - гражданам России», «Развитие агропромышленного комплекса»), [2] но и возможных перспективных приоритетных национальных проектах, которые могут быть посвящены модернизации различных отраслей экономики Российской Федерации и социально-бытовой сферы жизни ее граждан (например, «Развитие нанотехнологий», «Развитие машиностроительного комплекса», «Укрепление обороноспособности Российской Федерации и развитие предприятий военно-промышленного комплекса» и т.д.).

Представляется, что участие предприятий малого, среднего и крупного бизнеса в разработке и реализации приоритетных национальных проектов приобретает особую актуальность в свете разрастания глобального экономического кризиса, сопровождаемого сокращение доходной части российского бюджета, по ряду причин:

Во-первых, привлечение частных хозяйствующих субъектов к совместному финансированию приоритетных национальных проектов позволяет увеличить объемы финансирования, разгрузив расходную часть государственных и муниципальных бюджетов.

Во-вторых, большинство даже действующих приоритетных национальных проектов (например, «Доступное и комфортное жилье - гражданам России», «Развитие агропромышленного комплекса») предполагает участие в них предприятий, находящихся в частной собственности.[3, с. 5-9; 4, с. 11-15] В частности, большая часть предприятий жилищно-коммунального хозяйства и агропромышленного комплекса в современной Российской Федерации уже функционирует в качестве частных хозяйствующих субъектов.

В-третьих, осуществление частного бизнеса под свой страх и риск предполагает возможность использования предпринимателями более креативных и инновационных подходов в реализации различных мероприятий в рамках приоритетных национальных проектов, что делает их более конкурентоспособными и эффективными по сравнению с государственными учреждениями и предприятиями.

В-четвертых, совместная реализация государством и обществом в лице бизнеса приоритетных национальных проектов позволяет привлечь частные хозяйствующие субъекты к выполнению отдельных элементов государственных функций, консолидируя общественные и государственные усилия на пути экономической модернизации страны.[5, с. 55-56]

В-пятых, в связи с дефицитом большинства бюджетов субъектов страны и муниципальных образований, а также ограниченностью федерального бюджета в вопросах субвенций иных уровней бюджетной системы Российской Федерации, привлечение частного бизнеса для реализации мероприятий в рамках приоритетных национальных проектов и региональных (муниципальных) программ развития представляется одним из основных средств сглаживания различия в развитии отдельных регионов.

Однако эффективное взаимодействие органов государственного управления и бизнеса в целях реализации приоритетных национальных проектов на территории Российской Федерации осложнено рядом проблем.

Во-первых, на федеральном, региональном и местном уровне отсутствует четкое законодательное регулирование взаимодействия государства и частного сектора в части реализации государственных программ развития (в частности, приоритетных национальных проектов). Кроме того, несмотря на то, что на федеральном уровне финансирование четырех вышеназванных национальных проектов составляет уже значительную часть от объема государственного бюджета, до сих пор не принят Федеральный закон «О приоритетных национальных проектах в Российской Федерации», который бы придал данным программам национального развития законный статус и значимость. [6, с. 97-99; 7, с. 124-129] 
Во-вторых, на законодательном уровне до сих пор не разработаны государственные программы развития реального сектора экономики в части его кредитования, субсидирования, финансовой поддержки.

B-третьих, в настоящее время достаточно усложнено получение частными хозяйствующими субъектами кредитов у банков, контролируемых государством, в связи с тем, что основная часть финансовой поддержки государства для преодоления последствий экономического кризиса по непонятным причинам направляется в банковский сектор (а в дальнейшем либо направляется на валютный рынок для осуществления спекулятивных операций с валютой, либо вымывается за рубеж в качестве осуществления российскими банками и иными финансовыми организациями платежей в пользу зарубежных банковско-кредитных организаций по ранее полученным кредитам). В тоже время, в США государство даже до кризиса, начавшегося в 2008 году, максимально сократило число посреднических звеньев между Казначейством США и предприятиями реального сектора экономики при получении субсидий, льготных кредитов и иных форм поддержки бизнеса в реализации программ модернизации американской экономики. [8] Правительство КНР предоставляет максимально выгодные условия кредитования частного производственного сектора при условии, что полученные денежные средства будут инвестированы в те отрасли экономики страны, которые являются приоритетными для экономического развития Китая и только в рамках реализуемых планов экономического развития государства. [9]

В-четвертых, значительно затрудняет возможность осуществления эффективного взаимодействия органов государственного управления и бизнеса отсутствие прозрачности подобных взаимоотношений, рост фактов коррупции, клановости в государственном и муниципальном аппарате, сращивание властной элиты (особенно на региональном уровне) и отдельных финансово-промышленных и даже преступных группировок. [10, с. 35] Данные обстоятельства мешают развитию конкурентных отношений и тормозят экономическое развитие страны.

В-пятых, в стране отсутствует четкая законодательная база, регулирующая возможности и пределы софинансирования мероприятий в рамках приоритетных национальных проектов из федерального, региональных и местных бюджетов. [11, с. 15-18] Кроме того, имеется необходимость разработки и реализации региональных приоритетных проектов раз- вития в отдельных субъектах Российской Федерации, которые следует финансировать совместно из федерального бюджета и бюджетов субъектов страны.

B-шестых, действующее законодательство не содержит четкого механизма оценки эффективности и результативности, как бюджетного финансирования приоритетных национальных проектов, так и расходования государственных средств, направляемых для кредитования частного сектора в рамках мероприятий, реализуемых для преодоления последствий экономического кризиса. В результате, по мнению ряда экономистов, были неоправданно потрачены десятки миллиардов долларов из золотовалютных резервов страны, которые не привели ни к росту объемов российской экономики, ни к обновлению ее производственных фондов. [9]

В-седьмых, в действующем законодательстве закреплена чрезвычайно мягкая ответственность должностных лиц органов исполнительной власти за нецелевое и неэффективное расходование бюджетных средств, направляемых на финансирование мероприятий в рамках приоритетных национальных проектов, а также для кредитования предприятий частного бизнеса, в части преодоления последствий экономического кризиса и проведения структурной модернизации российской экономики. Так, глава 30 Уголовного кодекса Российской Федерации (преступления против государственной власти, интересов государственной службы и службы в органах местного самоуправления) в качестве максимального размера наказания предусматривает двенадцать лет лишения свободы, а за преступления, предусмотренные статьями 285.1 и 285.2, только до пяти лет лишения свободы,[12] хотя практика расследования ряда уголовных дел в отношении государственных и муниципальных служащих показывает, что некоторыми их них допущено нецелевое использование средств государственных и муниципальных бюджетов, исчисляемое несколькими миллиардами рублей. [9] Кроме того, действующее уголовное законодательство не содержит института конфискации имущества как меры основного, либо дополнительного вида наказания.

В-восьмых, серьезные препятствия в осуществлении эффективного взаимодействия органов государственного управления и бизнеса создает отсутствие в стране отсутствие единого центра координации вопросов реализации приоритетных национальных проектов на территории Российской Федерации. Действующий на основе Указа главы 


\section{Национальная безопасность $4(27) \cdot 2013$}

государства Совет при Президенте Российской Федерации по реализации приоритетных национальных проектов и демографической политике имеет полномочия в основном совещательного характера и реального влияния на ход реализации мероприятий в рамках национальных проектов не оказывает. [13] Кроме того, основная нагрузка по организационно-техническому обеспечению мероприятий проектов лежит на Правительстве Российской Федерации. [14] На региональном уровне также отсутствует законодательная база по реализации приоритетных национальных проектов, и данные вопросы регулируются актами исполнительных органов власти субъектов России. [15]

В-девятых, взаимодействию органов государственного управления и бизнеса в рамках реализации приоритетных национальных проектов создает препятствия излишнее государственное вмешательство в вопросы частного бизнеса, его зависимость от государственного репрессивного аппарата. [16; 17] Глава государства неоднократно заявлял о необходимости снижения управленческого прессинга на частный бизнес, сковывающего предпринимательскую инициативу и создающего «кормушку» для нечистоплотных на руку чиновников. [1]

В-десятых, значительной проблемой мешающей повышению эффективности взаимодействия органов исполнительной власти и частного бизнеса является неиспользование положительного зарубежного опыта взаимодействия органов власти и предпринимателей при реализации проектов и программ развития экономики государства и преодоления последствий глобального экономического кризиса, особенно в части осуществления государственной поддержки реальному сектору экономики страны.

Для разрешения указанных проблем, препятствующих эффективному взаимодействию системы исполнительной власти и бизнеса в целях реализации приоритетных национальных проектов на территории Российской Федерации, следует разработать и реализовать ряд последовательных мероприятий.

Прежде всего, необходимо принять Федеральный закон «О приоритетных национальных проектах в Российской Федерации», где будет обозначены приоритеты экономического развития нашей страны, место и роль органов государственной власти и местного самоуправления в подготовке и реализации данных проектов. В рамках данного Федерального закона на уровне регионов и муниципалитетов следует разработать систему регионального и местного законодательства по содействию реализации национальных проектов. [18] Это позволит избежать несогласованности действий органов государственного и муниципального управления при реализации отдельных мероприятий в рамках национальных проектов.

Кроме того, следует сформировать единую систему по координации и контролю за реализацией мероприятий в рамках приоритетных национальных проектов, как в масштабах всей страны, так и на территории отдельных субъектов Российской Федерации и муниципальных образований. В этой связи, представляется обоснованным использовать отечественный и зарубежный опыт планирования и контроля за осуществлением развития экономики государства. Например, возможно создание единого центра по планированию экономического развития страны, аналогично ранее существовавшему Госплану СССР.

Необходимо расширить перечень приоритетных национальных проектов, дополнив их комплексными проектами развития отдельных конкурентоспособных и экономически эффективных отраслей российской экономики (в частности, «Развитие нанотехнологий», «Развитие машиностроительного комплекса», «Укрепление обороноспособности Российской Федерации и развитие предприятий военно-промышленного комплекса»). Это позволит, с одной стороны, обеспечить развитие реального сектора экономики, а с другой стороны, создаст дополнительный объем государственного заказа для частного бизнеса, предотвратив банкротство предприятий.

Кроме того, следует разработать ряд приоритетных национальных проектов, посвященных обеспечению экономической безопасности российского бизнеса от негативного и незаконного воздействия, как их иностранных конкурентов, так и иностранных государств и международных корпораций. Например, создание и реализация национального проекта «Обеспечение экономической безопасности Российской Федерации» позволит не только обеспечить национальную безопасность страны, но и всех иных национальных проектов, так как основным условием их последовательной реализации является стабильное финансирование, которое возможно лишь путем достижения последовательного поступательного роста объемов российской экономики. Отдельные полномочия по координации процессов реализации приоритетных национальных проектов в области обеспечения национальной безопасности 
России следует предоставить Совету безопасности Российской Федерации.

Необходимо обеспечить адекватный и тотальный контроль за эффективностью и результативностью осуществления мероприятий в рамках приоритетных национальных проектов. Основная роль в механизме подобного контроля должна принадлежать Президенту Российской Федерации, который будет координировать работу иных органов, осуществляющих надзор за реализацией национальных проектов. [19, с. 2-4] Во избежание нецелевого и неэффективного расходование бюджетных средств, направляемых на финансирование приоритетных проектов следует законодательно внедрить понятие аудита эффективности использование средств государственных и муниципальных бюджетов и деятельности органов государственного и муниципального управления. Данная разновидность управленческого аудита широко используется за рубежом и состоит в оценке эффективности деятельности органов исполнительной власти и иных организаций по выполнению государственных функций, использованию государственных ресурсов, а также принятие рекомендаций по совершенствованию их работы, причем его главной целью является повышение эффективности управления общественными ресурсами. [20] Аудит эффективности деятельности органов исполнительной власти следует поручить системе контрольно-счетных органов государственной власти во главе со Счетной палатой Российской Федерации.

Необходимо разработать систему мер государственной поддержки частных предприятий в реальном секторе экономики страны. Данную поддержку следует оказывать на конкурсной основе, отдавая приоритет экономическим программам, предусматривающим развитие инновационных, наукоемких отраслей экономики России с высокими показателями производительности труда. В связи с этим, выделению бюджетных средств частному бизнесу должны предшествовать государственная научная экспертиза программам развития и конкурсный отбор по заранее определенным критериям в рамках реализации отдельных приоритетных национальных и региональных проектов.

Необходимо ужесточить ответственность должностных лиц органов исполнительной власти за нецелевое и неэффективное использование средств государственных и муниципальных бюджетов, применяя к виновным лицам в качестве мер наказания значительные сроки лишения свободы и конфиска- цию имущества в качестве основного или дополнительного вида наказания, внеся соответствующие изменения в Уголовный кодекс Российской Федерации.

Следует упростить и сделать абсолютно прозрачной систему взаимоотношения бизнеса и государственных и муниципальных органов контроля и надзора. Кроме того, оказание публичных услуг предпринимателям со стороны органов государственного и муниципального управления следует осуществлять с применением современных информационных и организационных технологий, минимизирующих возможность осуществления злоупотреблений должностным положением со стороны должностных лиц органов власти (то есть максимально устранить влияние субъективного фактора во взаимоотношениях власти и бизнеса).

Представляется, что данные мероприятия позволят обеспечить эффективное взаимодействие органов государственного и муниципального управления и частного бизнеса в целях преодоления последствий экономического кризиса и реализации приоритетных национальных проектов на территории нашей страны, придав им особую значимость и статус в политическом процессе России. [21, с. 14-17]

\section{Библиография:}

1. Медведев Д. Национальные приоритеты: статьи и выступления [Текст] / Д.Медведев; ред. Г. Павловский. - М.: Издательство «Европа», 2008.

2. Послание Президента Российской Федерации В.В. Путина Федеральному Собранию Российской Федерации от 10 мая 2006 г. [Текст] // Российская газета. - 2006. - № 97.

3. Фахрутдинова, Е.Р. Реализация приоритетного национального проекта «Развитие АПК» в Российской Федерации на современном этапе [Текст] / Е.Р. Фахрутдинова // Вопросы экономики и права. - 2009. - № 3. - С. 5-9.

4. Симанович, Л.Н. Проблемные вопросы реализации приоритетного национального проекта «Доступное и комфортное жилье - гражданам России» [Текст] / Л.Н. Симанович // Юрист. 2008. - № 9. - С. 11-15.

5. Рамазанов, Т.Г. Реализация приоритетного национального проекта «Развитие АПК» как часть экономической функции государства [Текст] / Т.Г. Рамазанов // Закон и право. - 2008. - № 6. - C. 55-56. 
6. Кабышев, С.В. Конституционно-правовой режим реализации приоритетных национальных проектов [Текст] / С.В. Кабышев // Ученые записки юридического факультета. - 2008. № 11. - С. 97-99.

7. Матненко, А.С. Приоритетные национальные проекты: предпосылки, сущность и проблемы правового регулирования [Текст] / А.С. Матненко // Вестник Омского университета. - 2008. - № 4. - С. 124-129.

8. Выборный, В.В. Организация бюджетного процесса в США и России (организационноправовые аспекты) [Текст] / В.В. Выборный // Российская юстиция. - 2007. - № 10.

9. [Электронный ресурс]. Режим доступа: http:// www.delyagin.ru.

10. Куракин А.В. Административно-правовые аспекты пресечения коррупции в сфере исполнительной власти // Право и политика. - 2001. - №12. - С. 35.

11. Матненко, А.С. Софинансирование федеральных программ из региональных и местных бюджетов [Текст] / А.С. Матненко // Финансы. - 2008. - № 12. - С. 15-18.

12. Уголовный кодекс Российской Федерации от 13 июня 1996 г. № 63-Ф3 (в ред. от 6 декабря 2007 г.) [Текст] // СЗ РФ. - 1996. - № 25. - Ст. 2954.

13. Указ Президента Российской Федерации от 21 октября 2005 г. № 1226 «О Совете при Президенте Российской Федерации по реализации приоритетных национальных проектов и демографической политике» [Текст]// СЗ РФ. - 2005. - № 43. - Ст. 4374.

14. Федеральный конституционный закон от 17 декабря 1997 г. № 2-ФКЗ «О Правительстве Российской Федерации» [Текст] // С3 РФ. 1997. - № 51. - Ст. 5712.

15. Распоряжение главы администрации Краснодарского края от 19 января 2006 г. № 37-p «О peaлизации приоритетных национальных проектов в Краснодарском крае в 2006 году» // Система «Гарант».

16. Муравьева, Ю. «Наезды» государства на бизнес продолжаются [Текст] / Ю. Муравьева // Практическая бухгалтерия. - 2005. - № 2.

17. Сажина, Т. Бизнес не доверяет государству [Текст] / Т. Сажина // Расчет. - 2007. - № 8.

18. Ципалов Д.О. Приоритетные национальные проекты в контексте российской правовой политики: Автореф. дис. ... к.ю.н. [Текст]Ростов-на-Дону. - 2007.

19. Сергиенко, А. Надзор за реализацией приоритетных национальных проектов [Текст] / А. Сергиенко // Законность. - 2007. - № 5. - С. 2-4.

20. Цуциев, М. Внешний финансовый контроля необходимый атрибут государства (интервью с Н. Столяровым, ответственным секретарем Ассоциации контрольно-счетных органов России (АКСОР) [Текст] / М. Цуциев // Бюджет. -2007 . - № 7.

21. Устинкин, С.В., Алабин, Д.В. Приоритетные национальные проекты в политическом процессе России [Текст] / С.В. Устинкин, Д.В. Алабин // Власть. - 2009. - № 4. - С. 14-17.

\section{References (transliteration):}

1. Medvedev D. Nacional'nye prioritety: stat'i i vystupleniya [Tekst] / D.Medvedev; red. G. Pavlovskiy. - M.: Izdatel'stvo «Evropa», 2008.

2. Fahrutdinova, E.R. Realizaciya prioritetnogo nacional'nogo proekta «Razvitie APK» v Rossiyskoy Federacii na sovremennom etape [Tekst] / E.R. Fahrutdinova // Voprosy ekonomiki i prava. - 2009. - № 3. - S. 5-9.

3. Simanovich, L.N. Problemnye voprosy realizacii prioritetnogo nacional'nogo proekta «Dostupnoe i komfortnoe zhil'e - grazhdanam Rossii» [Tekst] / L.N. Simanovich // Yurist. - 2008. - № 9. - S. 11-15.

4. Ramazanov, T.G. Realizaciya prioritetnogo nacional'nogo proekta «Razvitie APK» kak chast' ekonomicheskoy funkcii gosudarstva [Tekst] / T.G. Ramazanov // Zakon i pravo. - 2008. - № 6. - S. 55-56.

5. Kabyshev, S.V. Konstitucionno-pravovoy rezhim realizacii prioritetnyh nacional'nyh proektov [Tekst] / S.V. Kabyshev // Uchenye zapiski yuridicheskogo fakul'teta. - 2008. - № 11. - S. 97-99.

6. Matnenko, A.S. Prioritetnye nacional'nye proekty: predposylki, suschnost' i problemy pravovogo regulirovaniya [Tekst] / A.S. Matnenko // Vestnik Omskogo universiteta. - 2008. - № 4. - S. 124-129.

7. Vybornyy, V.V. Organizaciya byudzhetnogo processa v SShA i Rossii (organizacionno-pravovye aspekty) [Tekst] / V.V. Vybornyy // Rossiyskaya yusticiya. - 2007. - № 10.

8. Kurakin A.V. Administrativno-pravovye aspekty presecheniya korrupcii $\mathrm{v}$ sfere ispolnitel'noy vlasti // Pravo i politika. - 2001. - №12. - S. 35. 
DOI: $10.7256 / 2073-8560.2013 .4 .2560$

При цитировании этой статьи сноска на doi обязательна

Экономическое обеспечение национальной безопасности

9. Matnenko, A.S. Sofinansirovanie federal'nyh programm iz regional'nyh i mestnyh byudzhetov [Tekst] / A.S. Matnenko // Finansy. - 2008. № 12. - S. 15-18.

10. Murav'eva, Yu. «Naezdy» gosudarstva na biznes prodolzhayutsya [Tekst] / Yu. Murav'eva // Prakticheskaya buhgalteriya. - 2005. - № 2 .

11. Sazhina, T. Biznes ne doveryaet gosudarstvu [Tekst] / T. Sazhina // Raschet. - 2007. - № 8.

12. Cipalov D.O. Prioritetnye nacional'nye proekty v kontekste rossiyskoy pravovoy politiki: Avtoref. dis. ... k.yu.n. [Tekst]- Rostov-na-Donu. - 2007.
13. Sergienko, A. Nadzor za realizaciey prioritetnyh nacional'nyh proektov [Tekst] / A. Sergienko // Zakonnost'. - 2007. - № 5. - S. 2-4.

14. Cuciev, M. Vneshniy finansovyy kontrolya - neobhodimyy atribut gosudarstva (interv'yu s N. Stolyarovym, otvetstvennym sekretarem Associacii kontrol'no-schetnyh organov Rossii (AKSOR) [Tekst] / M. Cuciev // Byudzhet. - 2007. - № 7.

15. Ustinkin, S.V., Alabin, D.V. Prioritetnye nacional'nye proekty $\mathrm{v}$ politicheskom processe Rossii [Tekst] / S.V. Ustinkin, D.V. Alabin // Vlast'. 2009. - № 4. - S. 14-17. 